P98 (continued)

interviewed discussed "benefits," "challenges," and outlined "key-strategies" for implementing a food hub model.

Conclusions and Implications: A food hub model could provide high-quality fresh produce to all residents and may satisfy community needs for an integrated alternative food system.

Funding: NYC Department of Health and Mental Hygiene; W.K. Kellogg Foundation.

\section{P99 A Simple Convenience Store SHELF (Supportive Healthy Environment for Life- promoting Food) Audit}

Megan Mullin, BS, memullin@syr.edu, Syracuse University, 413 Sims Hall, Syracuse, NY 13244; E. Yildirim, MS;

E. Kelly, MS; O. Brown, PhD, RD, Auburn University;

C. Byrd-Bredbenner, $P h D, R D$, Rutgers University;

L. Franzen-Castle, $P h D, R D$, University of NebraskaLincoln; G. Greene, $P h D, R D$, University of Rhode Island; K. Kattelmann, $P h D, R D$, South Dakota State University; T. Kidd, PhD, RD, Kansas State University; J. Morrell, PhD, $R D$, University of New Hampshire; M. Olfert, $P h D, R D$, West Virginia University; K. Riggsbee, University of Tennessee; K. Shelnutt, PhD, RD, University of Florida; A. White, $P h D, R D$, University of Maine; T. Horacek, $P h D$, $R D$, Syracuse University

Objective: The Convenience Store SHELF (Supporting Healthy Environment for Life-promoting Food) Audit assessed the supports and healthfulness of foods sold in corner/drug/bodegas/dollar stores.

Design, Setting and Participants: Each audit item was scored using a five-point semantic-differential scale (1=provides little or no support for healthy foods, $5=$ provides high support for healthfulness). Audited items included: fresh, processed and frozen fruits and vegetables; low-fat dairy products, healthy staples and frozen meals; healthy food selection systems, items sold in check-out areas, portion/cup sizes, and pricing. SHELF was pilottested with experts/users to improve conceptualization and wording. Researchers completed video training, practiced, and achieved acceptable inter-rater reliability $(80 \%$ minimum) before conducting assessments.

Outcome Measures and Analysis: Data were analyzed with inter-class correlations (ICC), Latent class analysis and ANOVA.

Results: Stores $(n=165)$ were evaluated in 14 states; ICC for each state $($ stores $=15$, range $=0.781-1)$. Latent class analysis revealed a three class solution. Class 1:Least Healthy consisted of $70 \%$ of stores, $11.88 \pm 5.75 \mathrm{SD}$ (range $=0-28$ ). Class 2:Moderately Healthy consisted of $22 \%$ of stores, $21.55 \pm 4.13 \mathrm{SD}$ (range $=13-32$ ). Class 3:Most Healthy consisted of $8 \%$ of stores, $37.84 \pm 5.61 \mathrm{SD}$ (ranges=23-57). There were no significant differences by state in class distribution, however, the probability of class distribution differed significantly by store type $\mathrm{F}(162,2)$ $=3.356, \mathrm{p}<.05$.
Conclusions and Implications: SHELF distinguished the healthfulness of the convenience store environment with less than $10 \%$ scoring healthy. Researchers could suggest healthier options and simple supports for consumers to store owners. Future research should assess a broader range of convenience store locations.

Funding: Syracuse University, Auburn University and experiment stations for each participating land grant institution.

\section{P100 Strategies Used by New York City School Gardeners to Operationalization the School Garden Integration Framework's Components}

Kate Gardner, MS, RD, kwg2104@tc.columbia.edu, Teachers College, Columbia University, 525 West 120th Street, Box 137, New York, NY 10025; P. Koch, EdD, RD; I. Contento, $P h D$

Objective: The School Garden Integration Framework (SGIF) was developed to represent how gardens become well integrated into New York City elementary and middle schools. This study analyzed how schools operationalized the framework's 19 components to provide guidance on how other schools can utilize the SGIF effectively.

Design, Setting and Participants: Participants at 21 schools with well-integrated school gardens in Manhattan, Brooklyn, and the Bronx completed a survey, observations, and semi-structured interviews during the 2013-2014 school year. Additionally, the researcher took photographs at each garden and collected additional documents (when available).

Outcome Measures and Analysis: Analysis of the survey was conducted with descriptive statistics, while analysis of the interviews, photos, observations and additional documents used qualitative techniques, including pattern matching, explanation building, and cross-case synthesis.

Results: Many strategies emerged for each of the SGIF domains, including: "resources and support" - delegating tasks within a garden committee; "physical garden" - facilitating garden activities that serve as an introduction for new volunteers; "student experience" - utilizing individual lessons rather than a curriculum; and "school community" - e.g. mobilizing parents by reducing barriers like time. Some guiding principles that emerged as particularly important for new school gardens included - such as, starting small, being persistent and creating a network of support.

Conclusions and Implications: Each of the strategies that emerged from this study can help direct and guide school gardeners to better implement the SGIF. The strategies and core principles identified can be used by school gardeners to strengthen existing and establish new school gardening programs, or by policymakers to implement policies that better support and reduce barriers to school gardening.

Funding: None. 